\title{
O DESIGN ASSOCIADO AO CONCEPT ART NO DESENVOLVIMENTO DE PERSONAGENS: um estudo de caso
}

\author{
Douglas Daniel Pereira; Mestrando em Design; PPGD - FAAC/UNESP \\ doug_black10@hotmail.com \\ Milton Koji Nakata; Professor Doutor; PPGD - FAAC/UNESP \\ milton@faac.unesp.br \\ Galdenoro Botura Junior; Professor Livre - Docente; PPGD - FAAC/UNESP \\ galdenoro@gmail.com
}

\begin{abstract}
Resumo: São diversas as áreas em que o concept art se associa ao Design, desde o desenho, até a produção e o desenvolvimento de protótipos. Este trabalho tem como objetivo apresentar uma breve revisão sobre concept art e sua aplicação no desenvolvimento e criação de personagens dentro do Design, observando as etapas de desenvolvimento, utilizando para isso ferramentas e técnicas tradicionais e digitais. Assim, este trabalho apresenta um estudo de caso, no qual as etapas de desenvolvimento de um personagem são apresentadas, desde a sua concepção até a criação de um protótipo final, para isso usa o caso do desenvolvimento de um personagem por meio de sketchs, análises de referências, pintura, pintura digital, modelagem digital e criação de protótipo físico.
\end{abstract}

Palavras-chave: Design, Concept Art, Personagens, Protótipos

\begin{abstract}
There are several areas where the concept art joins the Design, from design, to production and prototyping. This work aims to present a brief review of concept art and its application in the development and creation of characters within the Design, observing the development stages, using this traditional and digital tools and techniques. Thus, this paper presents a case study in which the stages of development of a character are presented, from its conception to creation of a final prototype, it uses the case of the development of a character through sketches, analyzes references, painting, digital painting, digital modeling and creation of physical prototypes.
\end{abstract}

Keywords: Design, Concept Art, Characters, Prototypes 


\section{INTRODUÇÃO}

Para compreendermos o Design de personagens e a sua importância na indústria do entretenimento nos dias de hoje é necessário o entendimento e o esclarecimento do termo concept art ou concept design.

O Concept Art é uma forma de ilustração em que o principal objetivo é transmitir uma representação visual de um projeto, ideia ou disposição para uso em filmes, games, animação ou quadrinhos antes que ele seja colocado no produto final. Concept Art é também referido como o desenvolvimento visual ou a concepção do conceito, esse termo também pode ser aplicado ao design de varejo, cenografia, design de moda e design arquitetônico. Não se sabe ao certo quem popularizou ou até mesmo inventou o termo Concept Art em referência à pré-concepção devido a ambiguidade do nome na melhor das hipóteses. Mas pode ter surgido como parte do design automotivo para carros-conceito, ou como parte da indústria de animação. Certamente, ambas as indústrias tiveram a necessidade de pessoas que fizessem esse trabalho, mesmo que o termo não fosse tão usado. As remissões para o termo concept Art podem ser encontradas e foram utilizadas pela Disney Animation já em 1930 " (WIKIPEDIA, 2012a).

Já Takahashi e Andreo (2011) atentam para o fato de que, na abordagem do processo do design de personagem, existe o momento da criação e desenvolvimento iterativo do personagem que por se tratar de uma etapa, extremamente crítica, encontra-se inserida no domínio do concept art.

O autor também apresenta o concept art como a conceituação visual de um determinado projeto. Pode-se dizer que este represente um guia visual/conceitual auxiliador de papel crucial no desenvolvimento do projeto. A metodologia do processo criativo do design de personagens apresenta-se como um processo iterativo de design (TAKAHASHI e ANDREO, 2011).

Uma vez que sua execução independe da técnica ou do nível de acabamento dando ao concept artista a liberdade para expressar todo o seu potencial abrangendo desde o mais grosseiro esboço até o trabalho finalizado em mínimos detalhes.

Este artigo tem o objetivo de apresentar uma breve descrição sobre o universo do concept art dando ênfase no desenvolvimento de um personagem utilizando ferramentas bi e tridimensionais com um intuito de apresentar as etapas de um projeto nessa área e a construção de um protótipo desse personagem.

\section{REVISÃO TEÓRICA}

\subsection{Concept Art}

Takahashi e Andreo, (2011) afirmam que o concept art, pode ser considerado como representações visuais que buscam a materialização de conceitos idealizados para a indústria de entretenimento (como filmes de animação, ação livre e jogos eletrônicos), de forma a auxiliar no desenvolvimento dos projetos, pois acelera e torna mais coesa a produção, tornando possível incorporar, alterar e interagir visualmente com as idéias propostas, além de que sua utilização pode definir e estabelecer os primeiros passos do projeto possuindo grande potencial para enriquecer a apresentação do mesmo para possíveis investidores.

Segundo a revista Zupi (2010 p. 04), o concept art, que no português pode ser traduzido como arte-conceito, trata de uma forma de arte completa, desafiadora e 
excitante, embora possa ser considerada a arte mais "invisível" aos olhos do público. É necessário destacar que concept art é algo que se difere da chamada Arte Conceitual (conceptual art), que representa uma abordagem do universo das artes plásticas. [Concept art é a] arte capaz de traduzir ou vender uma ideia, de representá-la de forma que uma história possa ser lida; seja o resultado um elemento, um personagem, um ambiente ou um mundo inteiro de sonhos. Essa forma de arte pode ser expressa pela ilustração, escultura e muitas outras são mais requisitadas hoje pela indústria de entretenimento sendo o âmago artístico por trás de um novo título de game ou filme vencedor de Oscar. Aqueles que assumem essa tarefa são altamente especializados, pois há uma demanda seleta para esse tipo de trabalho. A revista ainda cita que a habilidade mais importante de um concept artist (artista de conceitos) seria a habilidade de interpretação de ideias, tornando possível atribuir "vida" em um sonho e torná-lo acessível a um determinado público.

Pipes (2007) sugere que o estágio conceitual de um projeto é o momento em que existe mais liberdade para o designer, que pode esboçar "ideias loucas" antes de pensar na parte prática do projeto. Este momento possibilita a exploração de idéias criativas fundamentais para o design. Embora este autor direcione o livro para a área do design de produto, é possível utilizar a mesma linha de pensamento para o presente tópico, pois, assim como o design de produto, o concept art também visa um produto final, que seriam os filmes, animações, jogos eletrônicos e, em alguns casos, até mesmo peças publicitárias.

Um esboço de conceito, de acordo com Pipes (2007), pode ser definido, de forma teórica como um conjunto de dicas visuais para sugerir um determinado design para um observador informado, possibilitando ao último a compreensão da proposta, abarcando o design como um todo e suas características visuais específicas.

$O$ desenho de conceito explicita a mente do designer em funcionamento, em um processo iterativo, solidificando um pensamento, avaliando-o seguindo rumo a um design mais refinado. Segundo o autor é o momento em que o designer avalia as possibilidades futuras, procurando atribuir forma à incerteza.

Em um depoimento a revista Zupi (2010 p.37) Frederic St-Arnaud - artista de efeitos visuais para a indústria cinematográfica - conta que considera como o fator mais apreciativo do concept art é o fato de não existirem regras ou um processo específico a ser seguido, contanto que expresse de forma bem sucedida o conceito. St. Arnaud enfatiza que um bom concept artist deve ter uma boa noção em desenho, com um bom senso de perspectiva e de cores, necessita ser criativo e dominar variadas habilidades técnicas.

"[...] Eu acho que a nossa profissão chegou para vencer. Houve uma época que as pessoas pensavam que era apenas brincadeira de criança, mas agora nós somos profissionais completos, com fortes conhecimentos, e para mim é certamente um dos melhores trabalhos do mundo." afirma Pascal Blanché - diretor de arte da Ubisoft, indústria de games - em entrevista dada à Zupi (2010, p.81).

Destaca-se que o universo do concept art agrupa desde o desenvolvimento de diferentes elementos como personagens, cenários, acessórios, climatização, entre outros, os quais tendem a influenciar e interagir mutuamente. 


\section{OBJETIVO}

O trabalhp realizado teve como objetivo a criação de um personagem levando em consideração fatores fundamentais para a produção em design, como o estudo de desenho e o estudo dos softwares. O intuito foi criar, modelar e caracterizar personagem (criatura), atendendo as diferentes funções existentes dentro do mundo do Concept Art, como o uso do desenho, da pintura tradicional (Lápis grafite), da pintura digital, da modelagem digital e da da modelagem tradicional (Clay) desenvolvendo assim um protótipo do mesmo.

Dessa forma, buscando abranger esse universo de possibilidades, gerou-se uma sequência de etapas e ferramentas que um concept artista utiliza para trazer vida aos seus personagens, aplicando-as em um personagem em particular para exemplificar todo esse processo projetual.

\section{ETAPAS DE DESENVOLVIMENTO DENTRO DO CONCEPT ART}

\subsection{Sketch do personagem}

O personagem foi desenvolvido com o intuito de atingir a descrição criada para o mesmo.

Trata-se de uma criatura alienígena com a forma de um animal marinho "sereia" e algumas características humanóide e anfíbias.

Assim foi desenvolvido sketches (esboços) com a forma inicial do personagem (Figura 01).

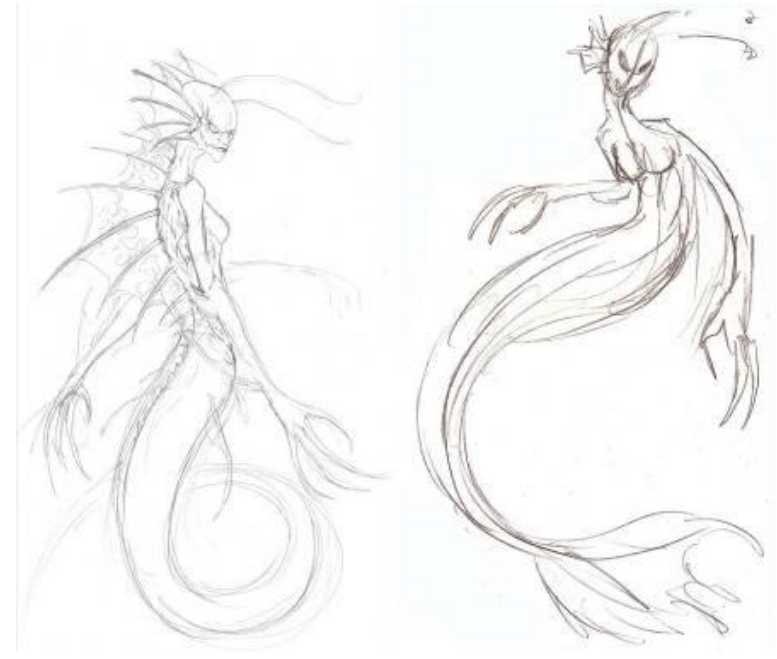

Figura 01 - sketches do personagem (elaborado pelo autor).

\subsection{Figura com referencias de animais e personagens}

Em seguida foi realizada uma pesquisa a fim de se obter imagens de animais que serviram de referencias e contribuíram para a criação e elaboração da forma final do personagem (Figura 02). 


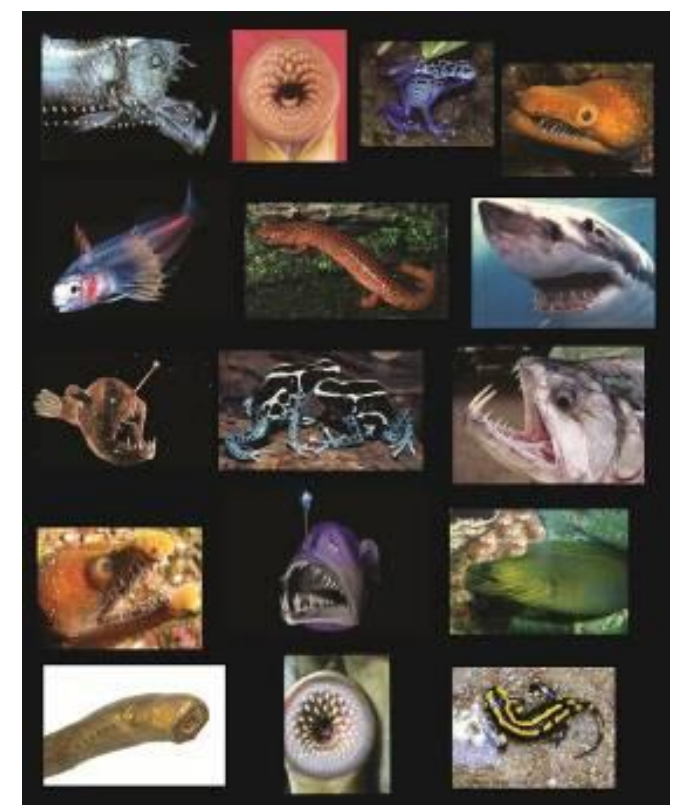

Figura 02 - Referencias de animais que auxiliaram no desenvolvimento do

\subsection{Traço final} personagem (imagens públicas da internet)

Uma vez desenvolvido o personagem, este teve uma arte finalização com o uso de canetas nanquim dando assim um acabamento ao desenho. Nessa etapa tanto formas como características do personagem já estavam definidas (Figura 03).

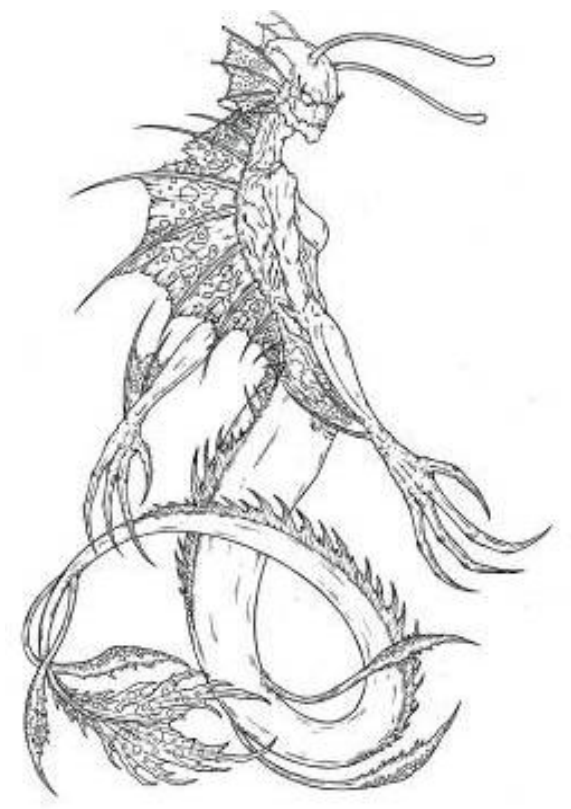

Figura 03 - Personagem já desenvolvido com traço a caneta (elaborado pelo autor).

\subsection{Pintura}

Nessa etapa definiu-se que a pintura do personagem se limitaria ao uso apenas do lápis (grafite) e caneta nanquim com o objetivo de marcar luz e sombra para que posteriormente fosse feita a aplicação de cor. 


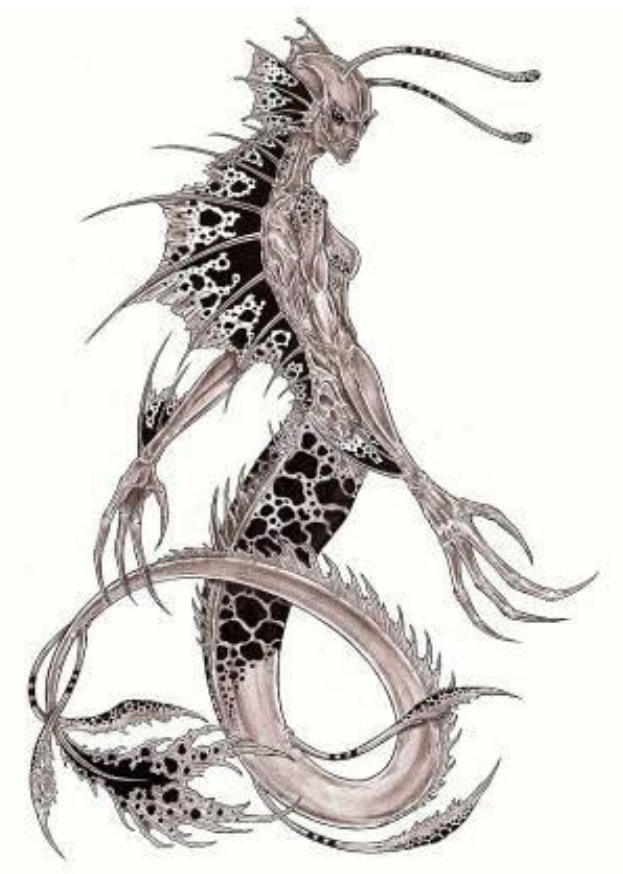

Figura 03 - Personagem com acabamento em grafite e caneta nanquim (elaborado pelo autor).

\subsection{Pintura Digital}

Utilizando as ferramentas digitais para a aplicação de cor foi realizado o estudo de cores com o intuito de gerar uma harmonia nas cores que comporiam o personagem e através do uso de softwares foi feita a sua pintura (Figura 04).

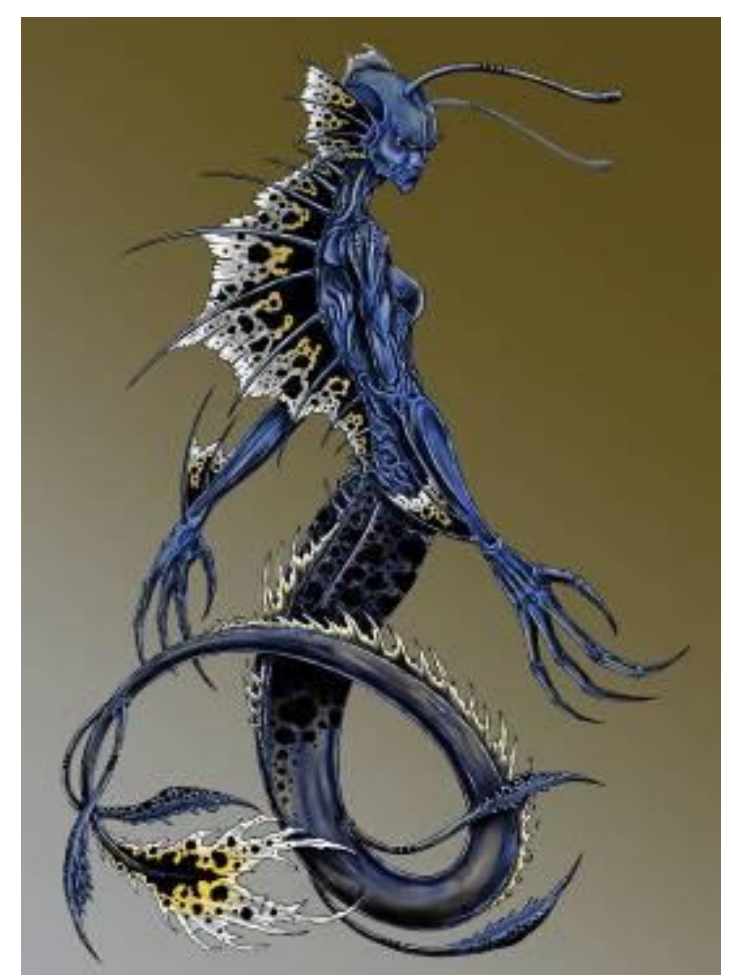

Figura 04 - Personagem finalizado em pintura digital (elaborado pelo autor). 


\subsection{Modelagem digital}

Para a modelagem digital foi utilizado um software específico que tem se tornado uma das ferramentas mais populares em termos de construção de modelos digitais fidedignos á realidade (Figura 05).

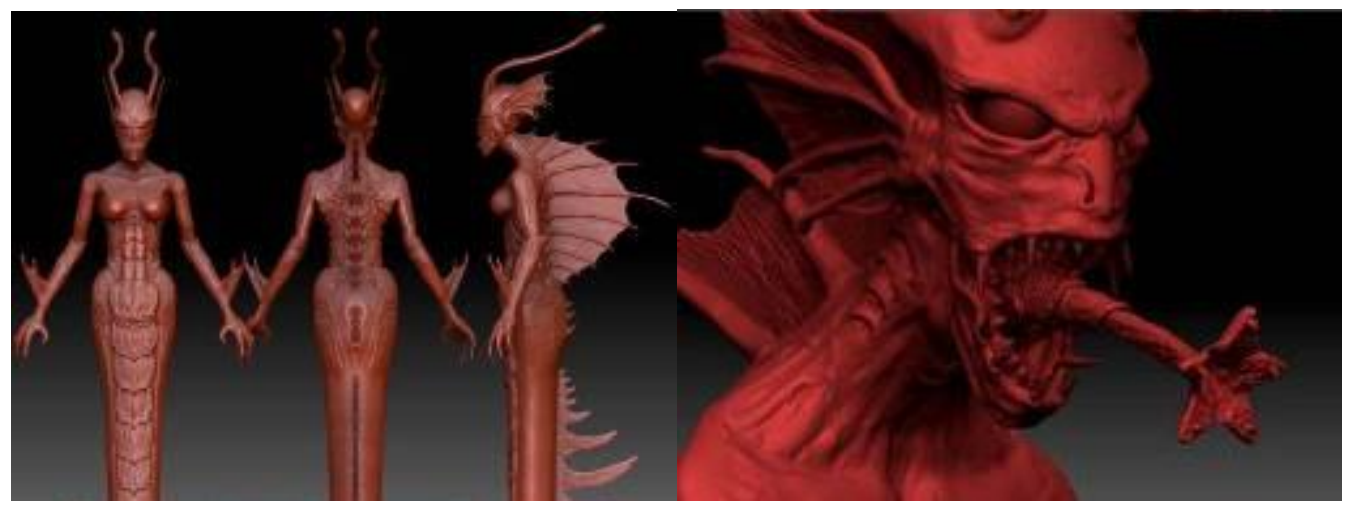

Figura 05 - Modelagem digital do personagem (elaborado pelo autor).

\subsection{Modelagem em Clay / Construção do protótipo}

O protótipo do personagem foi confeccionado utilizando o material conhecido como Clay que é uma argila sintética á base de óleo de uso artístico e industrial, feita para ser modelada ou esculpida com as mãos ou com o uso de ferramentas (estecas). É um material parecido com a plastilina (massinha), mas com propriedades para uso profissional na área de modelismo. Não seca nunca e pode ser reaproveitada indefinidamente, sem retração de material. Para facilitar o seu uso é aconselhável aquecer a massa no forno ou com um soprador térmico para amolecer ou derretê-la. A construção do protótipo em clay foi dividida em etapas (Figura 06).

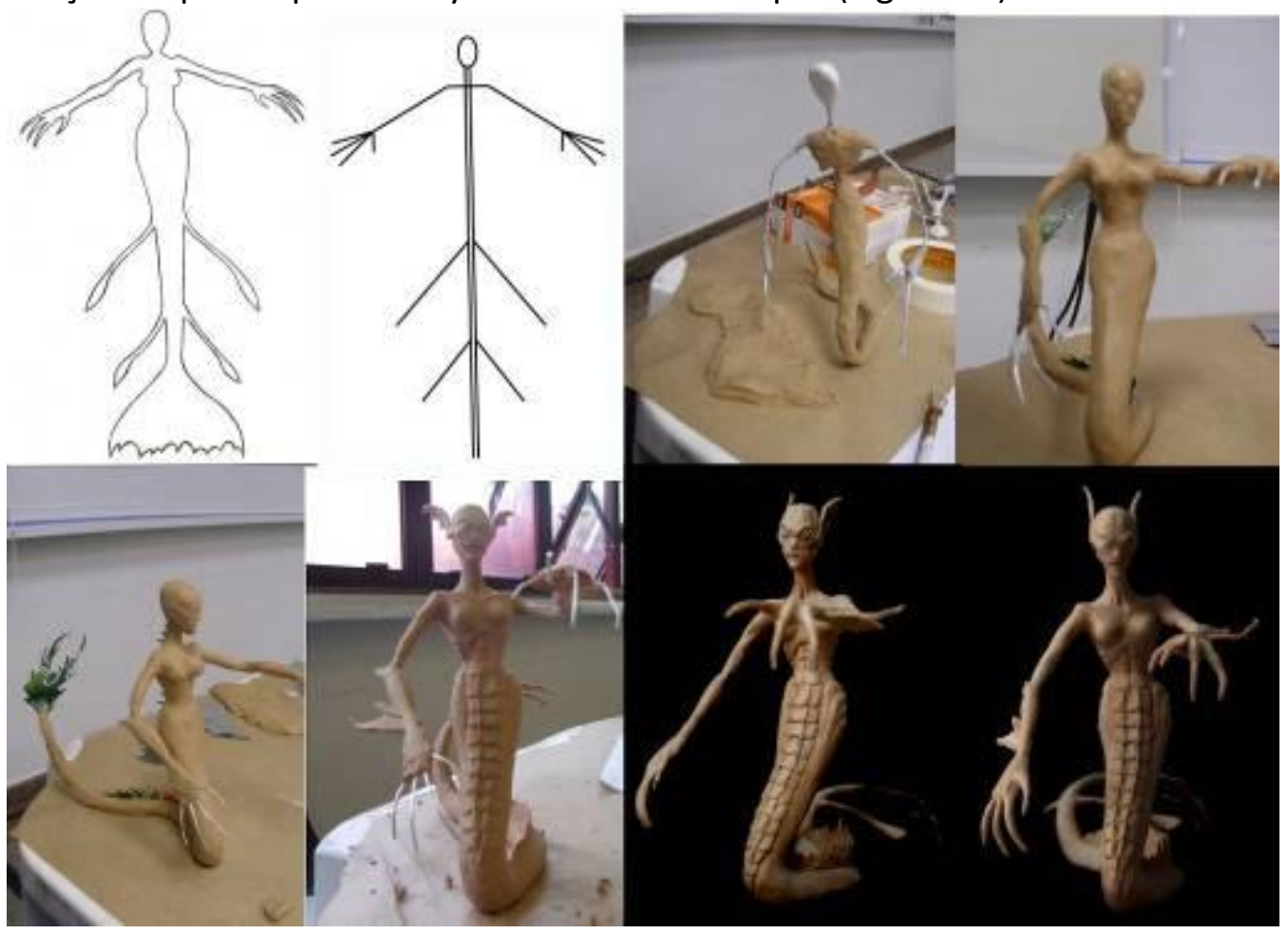

Figura 06: Etapas da construção do protótipo do personagem em Clay (elaborado pelo autor). 
- 1a Etapa

Uma vez criado o personagem, este foi transferido para um papel com o máximo possível de detalhes e informações de forma a estabelecer a escala que se desejava modelá-lo e criar vistas que auxiliassem nesse processo.

\section{- 2a Etapa}

Em seguida foi criada uma estrutura (esqueleto) de arame que serviu de reforço para a escultura a ser feita.

\section{- 3a Etapa}

Com o uso de papel alumínio e fita adesiva um engrossamento do esqueleto foi feito com o intuito de diminuir o gasto de material e o peso final da peça.

\section{- 4a Etapa}

Feito o volume inicial começou-se a cobrir a peça com o Clay, tendo por objetivo obter sua forma básica (blocagem). E seguida com o uso das estecas de acabamento começou-se a retirar o excesso de material dando mais forma ao personagem.

\section{- 5a Etapa}

Com o uso de estecas de detalhamento a peça foi detalhada ao máximo possível e depois com o uso de um pincel pequeno de ponta achatada a peça foi alisada com o D-limonene que é um álcool cítrico usado para dar acabamento final.

Após a construção do protótipo em Clay do personagem, foi feito o molde bipartido das partes do personagem utilizando silicone, obtendo assim o molde de suas partes.

Os moldes foram preenchidos com resina de poliuretano o que possibilitou a confecção de um protótipo final em um material rígido.

Este protótipo final ganhou acabamento com tinta acrílica e verniz (Figura 07, 08).

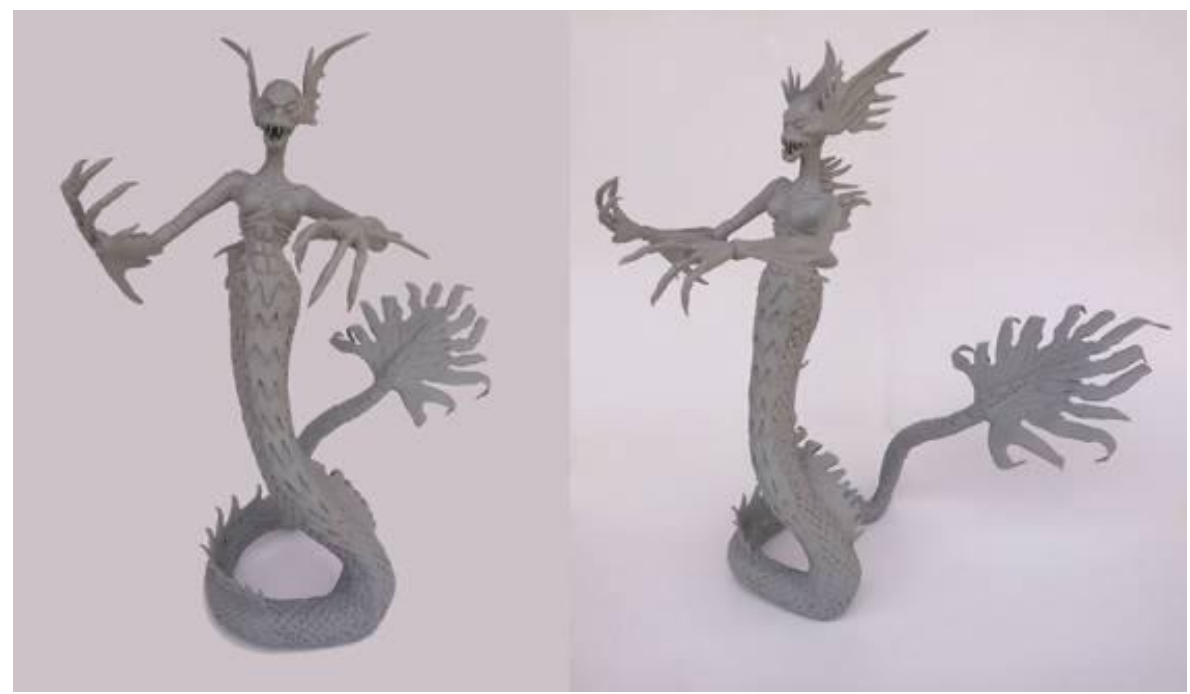

Figura 07 - Protótipo final em resina de poliuretano com acabamento em primer (elaborado pelo autor). 


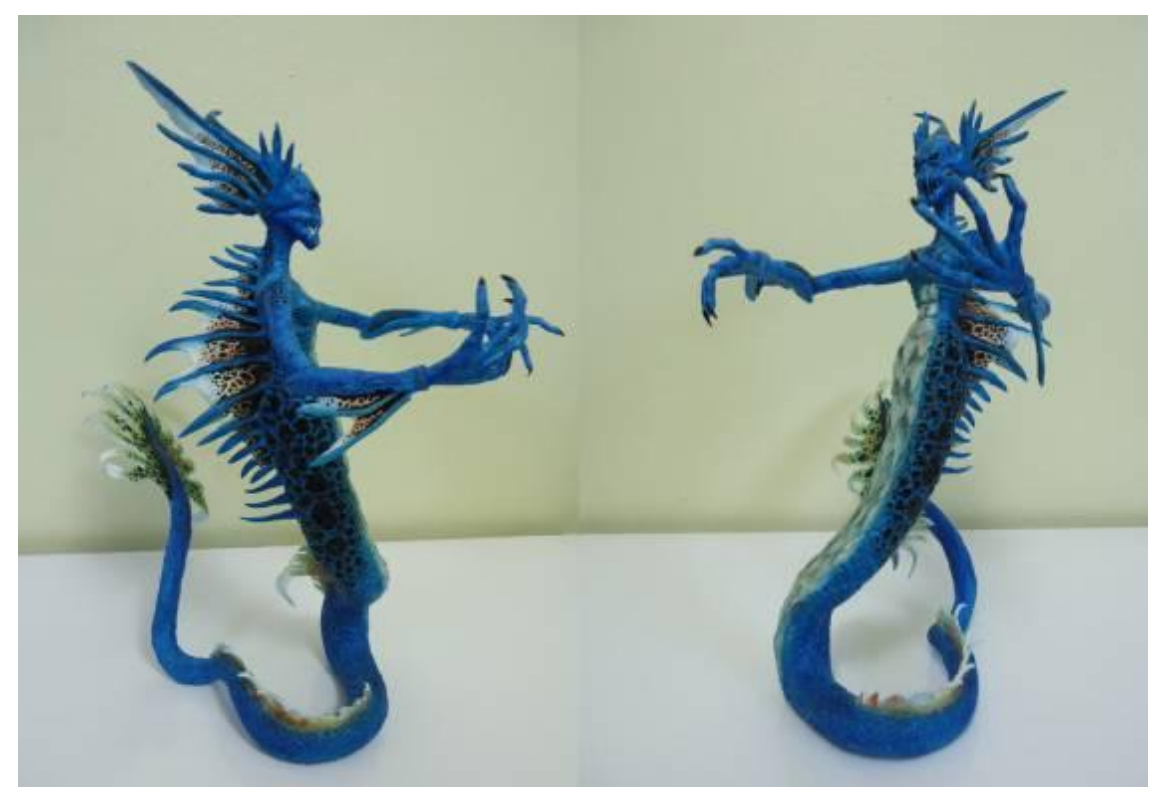

Figura 08 - Protótipo final em resina de poliuretano com pintura acrílica e acabamento em verniz (elaborado pelo autor).

\section{Considerações Finais}

Este artigo teve como proposta a apresentação e o estudo do concept art, visando o desenvolvimento de personagens. Fazendo uso de técnicas e ferramentas utilizadas pelos concept artistas

Uma vez que o concept art é algo de crucial importância para o desenvolvimento de projetos dentro do Design voltados para a indústria do entretenimento e de maneira particular o desenvolvimento de personagens que faz parte de um universo complexo oferecendo inúmeras possibilidades criativas a fim de se obter os melhores resultados possíveis para um projeto. Deve se também investir no estudo do desenho e em técnicas e maneiras de melhor representá-lo e o mais importante de tudo a habilidade de interpretação de idéias, assim como a tradução destas para o meio visual, tornando-as compreensível ao público a que se destina.

Isso nos leva a pensar o quanto seria interessante se as faculdades de Design espalhadas pelo Brasil criassem uma disciplina com temas focados no mercado de entretenimento.

Seria uma bela oportunidade de ampliar as possibilidades de atuação desses profissionais, abrindo assim portas para um vasto mercado que cresce a cada dia não só lá fora, mas também dentro do nosso país. Já que diversas empresas do segmento ampliam suas atuações no nosso país, sem falar dos estúdios cinematográficos que cada vez mais apostam em mão de obra nacional para o desenvolvimento dos seus projetos. Então, por que não apresentar esse mundo para os futuros designers como forma de possibilitar a esses jovens que ingressem nessa área e vislumbrem esse campo como uma possibilidade.

Assim, esse projeto tem a intenção de instigar após estes meses de dedicação ao mesmo uma pontinha de interesse a esse universo que configura cada dia mais algo de vital importância no desenvolvimento de projetos. 


\section{REFERÊNCIAS}

PIPES, A.; Desenho para designers: Habilidades de desenho, esboços de conceito, design auxiliado por computador, ilustração, ferramentas e materiais, apresentações, técnicas de produção. São Paulo: Edgard Blüscher Ltda.,2010.

TAKAHASHI, P. K.; ANDREO, M. C.. Desenvolvimento de Concept Art para Personagens. in: SBC - Proceedings of SBGames 2011.

WIKIPÉDIA, a enciclopédia livre. Apresenta texto sobre concept art, 2012. Disponível em: < http://en.wikipedia.org/wiki/Concept_art>. Acesso em 24 maio 2012.

ZUPI; Concept Art Issue. São Paulo: Zupi, n. 01.,2010. 